conseqnences of the administration of chloroform; but why should one patient exhibit this excess of alkaloidal substances in the urine and another not? It has long been known that even the normal products of digestion are poisonous if they are absorbed into the general circulation, and it is believed that these products are normally prevented from entering the general circulation by the action of the liver, which receives them from the intestinal veins and pours them out again in the bile. ${ }^{20}$ If the functions of the liver are at fault, the products not only of normal digestion but also of putrefaction taking place in the intestines may pass into the general circulation and may cause dangerous or fatal consequences, unless eliminated by the kidneys. A liver which is morbidly fatty cannot fail to be functionally inactive. The livers in most of these cases (probably all) were markedly fatty. This condition probably preceded the operations, because it is anlikely that it could have been produced by the action of the chloroform alone, owing to the short time of administration and the small amount of the anæsthetic used. Yet srom evidence adduced it seems to be certain that chloroform tends to produce fatty changes in the liver and elsewhere, and therefore it may aggravate this condition when already present. Theoretical though the explanation may be, I am unable to account otherwise for these fatalities after operation than by supposing: (1) that these deaths (in all but Cases 9 and 10) were due to auto-intoxication; (2) that a atty condition of the liver and therefore functional disturbance of the organ existed before the operations; and (3) that chloroform and operation shock combined aggravated the condition already present and thus loaded the system with toxic alkaloia's which the kidneys, notably in Cases 6 and 7 , were lanable to eliminate. The practical results of such Fiews are: (1) that in no case should chloroform be given to patients suffering from fatty liver; (2) that as it is impossible from physical signs and symptoms to do more chan surmise the existence of fatty liver we must rely on signs of functional inactivity of the liver, as indicated by the excess of alkaloidal substances present in the urine; and (3) what the precise nature of such alkaloidal substances and the best methods of detecting them must be left for further investigation.

The mortality in these cases shows the futility of the treatment adopted, which consisted in the free administration of alcohol combined with morphia, opium, and other anodynes. Such treatment, if the symptoms really depend apon fatty conditions, may be not only useless but positively barmful by actually increasing the state which it is supposed to remedy. Citrate of caffeine and carbonate of ammonia are not open to this objection, and perhaps might prove of service in similar cases. Also it is possible that active purgation might be beneficial. It is worthy of notice that the only patient who recovered (Case 10) suffered from most profuse hæmorrhagic diarrboa twenty-four hours after the operation. l'he probability that her symptoms depended upon mercuriai poisoning has already been suggested; still, it is by no cneans certain that the explanation is correct. Violent vomiting and profound collapse preceded the diarrhoea, and it is possible that the diarrhoea, whether or not produced by mercury, may have been salutary in her case. Some cases of supposed acute yellow atrophy of the liver are said to have recovered under active purgation.

Upper George-street, Bryanston-square, W.

\section{ON INFLUENZA AND SOME OF ITS SEQUELA.}

BY JOHN CRERAR, M.R.C.P. EDIN.,

GICE-PRESIDENT (FORMERLY PRESIDENT) OF THE BORDER COUNTIES BRANCH OF THE BRITISH MEDICAL ASSOCIATION.

Ox Dec. 19th, 1891, I communicated to the profession, in the columns of THE LANCET, what I then believed to be a safe, reliable, and effective treatment of influenza. My conviction as to the value of my recommendation was founded upon an unusually extensive experience of the treatment of this disease. Since then my increased opportunities supplemented by numerous testimonies from competent and reliable observers, practising widely apart from each other, have only served to confirm, beyond the shadow of a doubt, the state-

20 Dr. Lauder Brunton : Disorders of Digestion, 18ะ6, p. 17. ments I then made. I now beg leave to make further practical observations on the nature and treatment of this pest.

$I$ assume that influenza is of microbic origin; and $I$ have no doubt that, eventually, the labours of bacteriologists will enable them to prove this to a demonstration; it is also evident from the symptoms that the poison generated during the vital activity of those microbes delivers its chief and mosr deadly blow to the nervous system. Everyone is familiat with those symptoms; but there is one symptom which must have been observed by everyone conversant with this scourge, but which has hitherto remained undescribed, though, I hold, it is pathognomonic of the disease. I refer to that strange expression of the eyes which one could imagine might have been produced by a mixture of the peculiar look which is found in measles and that which is noticeable in a person under the influence of morphia. It is neither of those expressions taken singly, but a strange compound of the two. I propose, therefore, to call this singular symptom a " morbillomorphic" expression of countenance. It is found in cases where catarrhal symptoms are absent, not being dependent on such. It has been proved, by the experience of the recent epidemics, that influenza may exist with, and without, catarrhal symptoms, so that the term "epidemic catarrh" is inapplicable to the disease.

In my early use of the bicarbonate of potash in influenza I was carried away by the prevailing notion that this salt, in large doses, such as I was led to use, was not unattended with danger, from its supposed liability to depress the heart's action to an extreme degree. For this reason I watched the effect of my treatment with the utmost care, resolving to use a cardiac stimulant whenever there was any indication of heart failure. Among a very large number of cases I saw only two in which there was any alarming cardiac depression, and I am convinced, by experience and reflection, that the depression in those cases was not due to the salt, but to conditions peculiar to the patients. I wish, therefore, with all the emphasis I can, to denounce this superstition, which, I doubt not, has prevented some over-cautious practitioners from using a remedy which is at once simple, safe, reliable, and satisfactory.

I wish also to draw attention to another point of the greatest consequence. The bicarbonate treatment, if used early, will prevent debility and obviate sequelæ. The prevention of the sequelæ which usually follow influenza is, in importance, second only to the saving of life in the first instance. The forms of sequelæ I have chiefly in my mind are the mental distress and the physical debility, both of them often long-continued and not infrequently ending disastrously. The judicious use of the bicarbonate of potash will not permit those baneful camp-followers to appear at all, and will compel their removal when they have unhappily been allowed to effect a lodgment. Let me give an illustration from my own practice, as a painful example which has only too many parallels. I was called in to take charge of a female patient, who was suffering from influenza. She had a rather severe attack. She was also expecting to be confined shortly. This was in 1892 . During the previous epidemic she had been affected by the disease, but the medical man in attendance did not use my treatment; and ever since that time she was not only physically weak, but was continually tortured with thoughts of suicide. Under the bicarbonate treatment she made an excellent recovery. At the proper term she was confined in the usual way, and the convalescence was quite satisfactory. Subsequently I happened to meet her, when I used the physician's privilege and asked her whether she was still troubled by any of the distressing thoughts which had formerly made her life miserable. "No," she cheerfully replied, "all my bodily weaknesses are gone, and those dreadful thoughts have gone along with them." A tendency to mental derangement has been frequently seen as one of the least welcome sequelæ of influenza; and I am satisfied that in this case it was due to her first attack of the disease and had nothing to do with her pregnancy.

I have had independent testimonies of a similar character from practitioners who have adopted my treatment. I will give a short extract from each of two such testimonies. On Dec. 7th, 1893, an experienced practitioner wrote to me: "I have been using your treatment in every case lately, and I have had no acute case which has not cleared up, and no case which has developed serious manifestations in the way of sequelæ." Another practitioner of acknowledged ability, acuteness, and candour, and very extensively engaged in practice, wrote to me on Dec. $24 \mathrm{th}, 1893$, referring to the epidemic prevailing then in Edinburgh: "I have found the 
drug eminently successful; and, while such sequelæ as pneumonia are in no way apparently affected by its use, either favourably and certainly not unfavourably, others, such as the mental depression and physical languor, do undoubtedly yield to its continued exhibition. I am confident that we will never have a more trustworthy therapeutic agent for influenza than the bicarbonate" (of potash). This last-quoted gentleman previously informed me that they had had no sequelæ except in cases where the mischief had been done before they were called in; and I am aware that he has subjected my treatment to the most rigid clinical tests, so that his conclusions may be confidently accepted.

I have ascertained that some practitioners, while provisionally accepting my treatment, have not faithfully followed my directions for the use of the drug, and were thus led to inconveniences which they might have anticipated and avoided. It may not be amiss, therefore, if I give a short account of the usual way in which I treat my patients suffering from this disease. The patient ought to be confined to bed, and, the tendency to develop chest complications being so strong, the temperature of the room should be about $70^{\circ} \mathrm{F}$. The room itself ought to be large and well ventilated, but free from dranghts. The bowels should be acted on, and castor-oil in hot coffee or milk will do this office well. I give thirty grains (to an adult) of the bicarbonate of potash in a teacupful of milk every two or three hours, according to the nature of the attack, until the acute symptoms and fever have disappeared, which usually bappens in from four to six hours. In addition to the milk in which the salt is administered, the patient should be well supported with good beef-tea and nourishing soups from the first. On the subsidence of the fever the salt may be given thrice daily in undiminished doses, and continued for two or three days. Care should be taken not to allow the patient to leave the warm room until convalescence is fully established.

I am fully aware that my treatment of this disease has been very extensively adopted by the profession; but I am also aware that very many-not a few in eminent positionsare still working on the old lines, with the old disastrous results. Should any considerable number of the latter perchance cast their eyes on this paper, I cherish the hope that the bicarbonate of potash treatment of influenza will, in consequence, be diffused over an ever-increasing area, for I am confident that when once adopted it will never be lightly relinquished for another.

Castle Hill, Maryport.

\section{ON MENTAL THERAPEUTICS.}

\section{BY A. T. SCHOFIELD, M.D.BRUX., L.R.C.P.LOND., M.R.C.S. ENG.,}

HON. PHYSICIAN TO FRIEDENIIEIM HOSPITAL.

THERE can be no doubt in the minds of thoughtful men as to the fact of the great influence-therapeutic influencethat the mind has over the body. Many monographs have been written from time to time on this subject, which is also incidentally touched upon with more or less brevity in various works on the mind and brain, but as regards its practical application is largely left in the hands of quacks, who are allowed by the medical profession to exploit at will the rich fields of scientific and pecuniary interest which it at present affords to those who are sufficiently clever and unprincipled to work the latter without scruple. It is difficult to understand why such a powerful means of cure is so systematically neglected and even igrored by the profession, with the unhappy results described above of leaving it to be used illegitimately by others. I suppose it is because mental therapeutics have been practically for so long the real modus operandi of the vast army of charlatans that the whole subject has acquired such a bad name that most men fear for their own reputation if they touch it; indeed, it is only because I bave been taught practically so much of its real value, and feel so strongly that its continued neglect is no small blot upon the present system of medical training, that I venture with some trepidation to call attention to its almost universal neglect. While its power is everywhere seen and felt in the out-patient department, in the hospital ward, in the consulting-room and by the sick-bed, it is seldom spoken about and still less often taught, though few are bold enough to attempt to deny its potent powers for good. If one turns from the physician's daily life to his library, one still fails to find in any modern system of medicine the subject fairly and fully recognised. There are many manuals and systems of thera. peutics, but where is the great therapeutic power of the mind given its due place and prominence? It is the same if one listens to the teaching, clinical or otherwise, in the hospitals and class-rooms. Students listen with rapt attention to the powers of cocaine, piperazine, phenocoll, and the whole round of well-advertised modern drugs, but how often is their attention directed, save in ridicule, to this mighty curative agent that in its powers pretty well balances the whole pharmacopcia-the mind? Does any practical medical man doubt these powers? Is be not aware of the ingredient "faith," which, if added to his prescriptions, makes them often all-powerful for good? Does he not know the value of strongly asserting that the medicine will produce such and such effects is a powerful means of securing them? Has he never witnessed the therapentic value through the mind of the dentist's waiting-room in curing tootbache, or of the consultant's spacious dining-room and back numbers of Punch, combined with the physician' august presence in the consulting-room? And has he not seen how much more efficacious the very same drugs have proved when prescribed in such solemn surroundings than in his own humbler environment and less august presence? If then, this power is so well known, why, in the name of common-sense, should it be pooh-poohed and ignored as it is? It has its laws of action, its limitations, its powers for good and for evil : would it not greatly help the medical student if these were indicated to him by his lawful teachers instead of his being left to glean them uncertainly from the undoubtec? successes of the large army of irregulars? Let me bring these suggestions to a point in order to give them a practica? bearing and illustrate the value of legitimate mental therapeutics by briefly enumerating some part of the meslicinal, or at any rate therapeutic, value of the common mantelpiece striking clock-I say "clock" in preference to "watch" because it is distinctly of greater value, and I say "mantel. piece " instead of "eight-day" or " hall" clock for the same reason. I would also say "striking clock," with the half. hours and quarters, if possible, as being of still greater efficacy. It is perfectly astounding to see the cures that can be assisted, and in some cases altogether effected, by this agency, the power of which is obviously purely mental.

Sir Dyce Duckworth, without dwelling on the value of mental therapeutics, has pointed out an instance of their valuable use by means of the clock in urging the great. efficacy, in cases of persistent vomiting, of giving the liquid food in teaspoonfuls every five minutes by the clock. There can be no doubt that food thus given is readily retained, and still more so if the clock can be clearly observed by the patient himself from the bed. At the exact time the mind, acting through the brain, enables the stomach (perhaps by some inhibitory power over the vomiting certre in the medulla) to retain the food.

The value of the clock in labour is not universally bnown, but it is very marked. In a large proportion of cases, when the pains are tedious and irregular in force anc frequency, they can be made quite regular, to the great advantage of all concerned-patient, infant, and medical attendant-by the aid of the clock. The law has only to. be firmly laid down of "a pain every five minutes, of two minutes' duration, with a three minutes' interval," for it to be obeyed in a majority of such cases. When by the clock the time arrives for the pains to begin it should be clearly announced to the patient, and the fundus should at the same time be gently pressed by the hand on the abdomen, the nurse being meanwhile ordered to give, officiously, any needed assistance ; and the pain, being thus expected and prepared for, commences, and should be kest up for the two minutes, complete rest being then giren for the remaining three, when the process is renewed. After two or three pains are thus regularly induced the routine is established, and there is no difficulty in continuing regularly till the close of the second stage. The essence of success lies in invoking the therapentic aid of the clock. Of course, there are patients who are not amenable to this form of treatment, as there are others who cannot tolerate quinine or opium.

Again, when the child is born what a boon, what a fountain of health, the clock may become to both mother and child. The nursery, when the value of the clock is unknorn. is a scene of confusion and bad management, however fult the little cupboard may be of drugs. What peace ans 